\title{
TU/e EmonONEN

\section{All-optical network subsystems using integrated SOA-based optical gates and flip-flops for label-swapped networks}

\section{Citation for published version (APA):}

Kehayas, E., Seoane, J., Liu, Y., Martinez, J. M., Herrera Llorente, J., Van Holm-Nielsen, P., Zhang, S., McDougall, R., Maxwell, G. D., Ramos, F., Marti, J., Dorren, H. J. S., Jeppesen, P., \& Avramopoulos, H. (2006). All-optical network subsystems using integrated SOA-based optical gates and flip-flops for label-swapped networks. IEEE Photonics Technology Letters, 18(16), 1750-1752. https://doi.org/10.1109/LPT.2006.880784

DOI:

10.1109/LPT.2006.880784

Document status and date:

Published: 01/01/2006

\section{Document Version:}

Publisher's PDF, also known as Version of Record (includes final page, issue and volume numbers)

\section{Please check the document version of this publication:}

- A submitted manuscript is the version of the article upon submission and before peer-review. There can be important differences between the submitted version and the official published version of record. People interested in the research are advised to contact the author for the final version of the publication, or visit the $\mathrm{DOI}$ to the publisher's website.

- The final author version and the galley proof are versions of the publication after peer review.

- The final published version features the final layout of the paper including the volume, issue and page numbers.

Link to publication

\section{General rights}

Copyright and moral rights for the publications made accessible in the public portal are retained by the authors and/or other copyright owners and it is a condition of accessing publications that users recognise and abide by the legal requirements associated with these rights.

- Users may download and print one copy of any publication from the public portal for the purpose of private study or research.

- You may not further distribute the material or use it for any profit-making activity or commercial gain

- You may freely distribute the URL identifying the publication in the public portal.

If the publication is distributed under the terms of Article 25fa of the Dutch Copyright Act, indicated by the "Taverne" license above, please follow below link for the End User Agreement:

www.tue.nl/taverne

Take down policy

If you believe that this document breaches copyright please contact us at:

openaccess@tue.nl

providing details and we will investigate your claim. 


\title{
All-Optical Network Subsystems Using Integrated SOA-Based Optical Gates and Flip-Flops for Label-Swapped Networks
}

\author{
E. Kehayas, J. Seoane, Y. Liu, J. M. Martinez, J. Herrera, P. V. Holm-Nielsen, S. Zhang, R. McDougall, \\ G. Maxwell, F. Ramos, J. Marti, H. J. S. Dorren, P. Jeppesen, and H. Avramopoulos
}

\begin{abstract}
In this letter, we demonstrate that all-optical network subsystems, offering intelligence in the optical layer, can be constructed by functional integration of integrated all-optical logic gates and flip-flops. In this context, we show 10-Gb/s all-optical 2-bit label address recognition by interconnecting two optical gates that perform XOR operation on incoming optical labels. We also demonstrate 40-Gb/s all-optical wavelength-switching through an optically controlled wavelength converter, consisting of an integrated flip-flop prototype device driven by an integrated optical gate. The system-level advantages of these all-optical subsystems combined with their realization with compact integrated devices, suggest that they are strong candidates for future packet/label switched optical networks.
\end{abstract}

Index Terms-Address recognition, Mach-Zehnder interferometer (MZI), optical flip-flop, optical label swapping (OLS), packet switching, semiconductor optical amplifier (SOA), wavelength conversion.

\section{INTRODUCTION}

$\mathbf{N}$ EW communication standards such as multiprotocol label swapping [1] have been reported, for solving the mismatch between fiber capacity and router packet forwarding capacity. Optical label swapping (OLS) [2]-[5] has been recently reported where intelligent functionalities such as label processing and routing are realized through electronics and advanced, yet complex, integrated devices. Considerable work on OLS labeling has been also reported for coding low-rate labels in different modulation [2] using customized transmitter designs. Up to now, packet routing with lower bit-rate labels has been reported, ranging from megabits per second up to $10-\mathrm{Gb} / \mathrm{s}$ labels [3], [4]. In the last years, research on all-optical signal processing has been fueled through research projects

Manuscript received April 7, 2006; revised June 8, 2006. This work was supported by the European Commission through projects IST-LASAGNE (FP6-507509), IST-e-Photon/ONe (FP6-001933), and IST-e-Photon/ONe+ (FP6-027497).

E. Kehayas and H. Avramopoulos are with the Photonics Communications Research Laboratory, National Technical University of Athens, Zografou, GR 15773 Athens, Greece (e-mail: ekeha@ mail.ntua.gr).

J. Seoane, P. V. Holm-Nielsen, and P. Jeppesen are with COM-DTU, Department of Communications, Optics and Materials, Technical University of Denmark, DK 2800 Kgs. Lyngby, Denmark.

Y. Liu, S. Zhang and H. J. S. Dorren are with the COBRA Research Institute, Eindhoven University of Technology, $5600 \mathrm{MB}$, Eindhoven, The Netherlands.

J. M. Martinez, J. Herrera, F. Ramos, and J. Marti are with the Nanophotonics Technology Center, Universidad Politécnica de Valencia, 46022 Valencia, Spain.

R. McDougall and G. Maxwell are with the Centre for Integrated Photonics, Adastral Park, Ipswich IP5 3RE, U.K.

Digital Object Identifier 10.1109/LPT.2006.880784

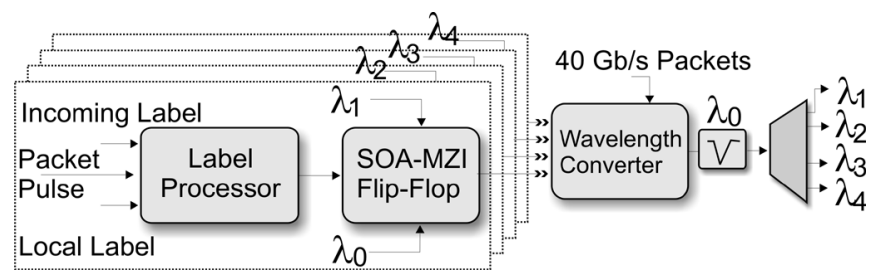

Fig. 1. Concept diagram of all-optical label processing and forwarding.

[6]-[8] and the creation of companies offering integrated devices. In order for optical switching to emerge as a viable technological solution, all-optical network subsystems implementations/designs must be capable of processing high-rate packet traffic with bit-serial labels, therefore yielding increased bandwidth utilization while avoiding customized transmitter configurations. These subsystems must also be implemented using a single cost-effective photonic integration technology based on monolithic or hybrid integration or combination of both and not customized and costly solutions. In this letter, we analyze two all-optical network subsystems; a label processor capable of recognizing 10-Gb/s incoming labels and a $40-\mathrm{Gb} / \mathrm{s}$ optically controlled wavelength converter, driven by a flip-flop prototype device. These subsystems can operate at high-speed with low guardband requirements and are implemented using a single integration technology. Research on integration of multiple gates on a chip [7] suggests that the subsystems could be integrated on the same chip, avoiding fiber-to-chip coupling and reducing packaging and pigtailing costs.

\section{All-Optical Routing CONCEPT}

Fig. 1 shows the block diagram of the processing core of an all-optical label swapper (AOLS) [6]. The system consists of an array of label processors and optical flip-flops connected to a $40-\mathrm{Gb} / \mathrm{s}$ wavelength converter. All-optical label extraction, single pulse extraction, and local label generation using semiconductor optical amplifier Mach-Zehnder interferometer (SOA-MZI) gates is performed as described in [6]. Each label processor compares the incoming label with one permutation and generates a single pulse if a match occurs [6]. Each branch of label processors is connected to an all-optical flip-flop, emitting at two wavelengths $\left\{\lambda_{0}, \lambda_{1 \ldots 4}\right\}$, for the case of a $4 \times 4$ AOLS node. The common wavelength $\lambda_{0}$ is filtered, allowing one of the four wavelengths to propagate depending on which label generated the matching pulse. The flip-flop device is based on two coupled MZI gates, as shown in Fig. 2(a) in 


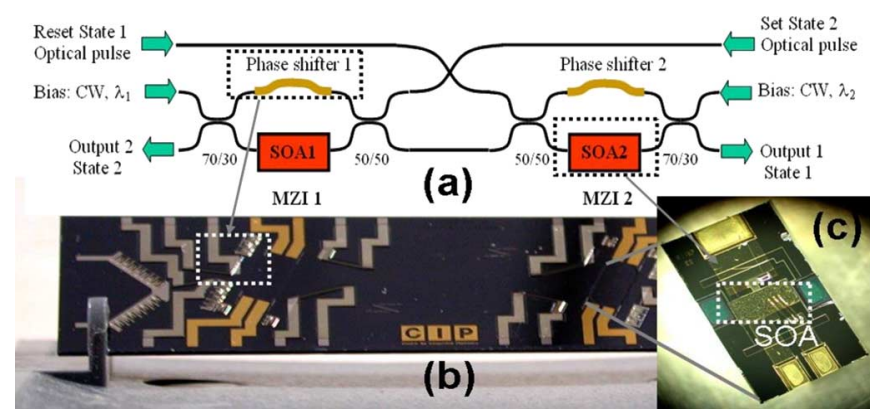

Fig. 2. Developed flip-flop using hybrid technology: (a) schematic of device, (b) planar silica motherboard, (c) daughterboard with twin SOAs flip chipped and wirebonded. (Color version available online at http://ieeexplore.ieee.org.)

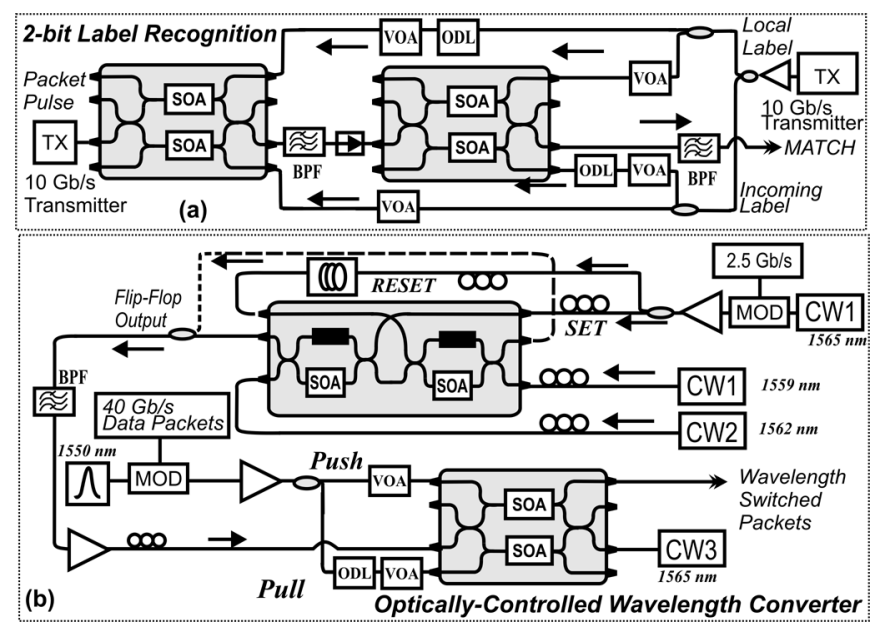

Fig. 3. Experimental setups of the all-optical network subsystems, (a) all-optical label processor and (b) optically controlled wavelength converter.

order to obtain a very fast switching time. Each gate is powered by one continuous-wave (CW) signal, forming a bistable element with two wavelength states. Toggling between states is achieved by injecting a pulsed signal to one of the two gates to "set" the device and a delayed version to "reset" to the previous state. The amount of delay between set and reset pulses defines the duration for which the device is in the set state, and for the AOLS scenario, it is equal to the packet length. A prototype device comprising two flip-flops on a single chip was fabricated by the Center for Integrated Photonics. Fig. 2(b) shows the silica waveguide motherboard showing the two MZI structures. Fig. 2(c) shows the precision-diced daughterboard with flip-chipped twin SOA devices. Packet routing is achieved by connecting the output of the flip-flop to an SOA-MZI wavelength converter. Depending on which label processor generated a matching pulse, the appropriate flip-flop is set, emitting at one of the four wavelengths to which the payload will be converted, as shown in Fig. 1.

\section{IMPLEMENTATION OF SUBSYSTEMS}

Fig. 3 shows the two experimental setups that were used to demonstrate each subsystem individually. Fig. 3(a) shows the experimental setup of the label processor. A suitable transmitter was implemented, generating the label patterns and the clock signal used as input to the optical gates. A pulse-generating laser was used as the clock source, whereas the labels and control signal were modulated using high-speed pattern generators. The

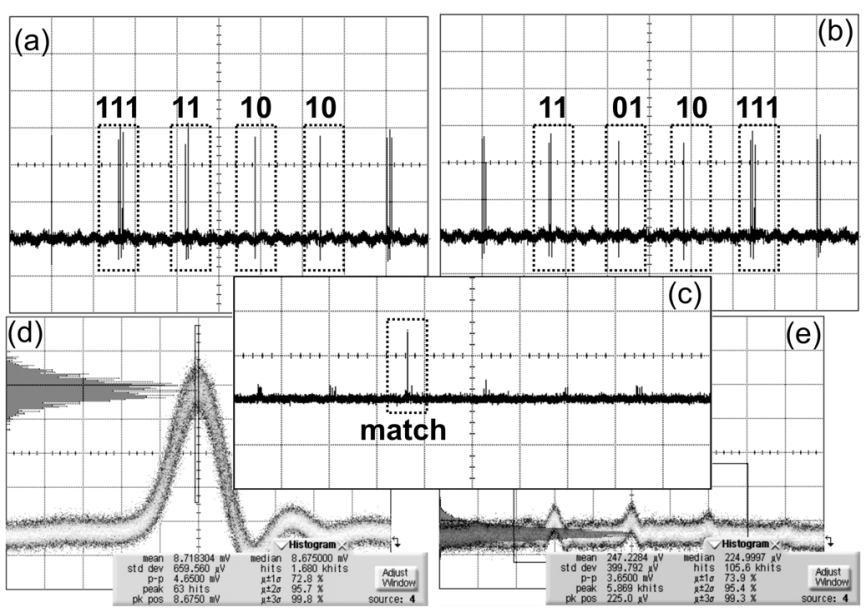

Fig. 4. Experimental results of label processor (a) incoming labels, (b) local labels, (c) match pulse, and (d), (e) show corresponding " 1 " and " 0 " levels.

label processor consists of two cascaded SOA-MZI optical gates configured to perform XOR operation on the incoming and local labels. A matching pulse appears at the output of the subsystem only if a complete match occurs. Polarization control was only necessary at the input of each gate, since the SOAs used had low polarization dependence. The optical delay lines were used to fine-tune the synchronization between interacting signals within the optical gates and the variable optical attenuators were used to adjust each signal power for optimized switching within the SOAs.

Fig. 3(b) shows the experimental setup for the tunable wavelength converter used to demonstrate the concept of all-optical routing. Two CW optical sources emitting at 1559 and $1562 \mathrm{~nm}$ were used for providing the two states to the optical flip-flop prototype. A pulsed signal was also generated by modulating a CW laser emitting at $1565 \mathrm{~nm}$ that acted as the control pulse providing the SET and RESET signals. The signal had a pulsewidth of $400 \mathrm{ps}$ and a period of $13 \mathrm{~ns}$. The flip-flop output was connected to the wavelength converter, realized using an SOA-MZI gate operated in push-pull mode. A counterpropagating holding beam was also used for removing transients within the SOAs and reshaping the generated $\mathrm{CW}$ signal from the flip-flop. Finally, a $40-\mathrm{Gb} / \mathrm{s}$ pattern generator was used to modulate data on short pulses provided by a pulse generating laser. Depending on the measurement required, the pattern generator was programmed to produce continuous or packet-mode $40-\mathrm{Gb} / \mathrm{s}$ data.

\section{RESULTS}

Fig. 4 shows typical experimental results of the $10-\mathrm{Gb} / \mathrm{s}$ label processor. Fig. 4(a) and (b) shows 2-bit label combinations to be compared. Each label is spaced 2.7 ns, whereas the "111" combination was included for assisting the synchronization of signals during the experiment. The local and incoming labels were synchronized so as " 01 " coincides with " 10 " giving a complete match. The generated matching pulse at the output of the label processor is shown in Fig. 4(c) verifying the operation of the subsystem. Fig. 4(d) and (e) shows the eye diagrams of " 1 " and " 0 " levels, revealing an extinction ratio of $10 \mathrm{~dB}$. Figs. 5 and 6 show experimental results of the 40-Gb/s optically controlled wavelength converter. In order to assess the quality of the CW signal provided by the flip-flop, static bit-error-rates 


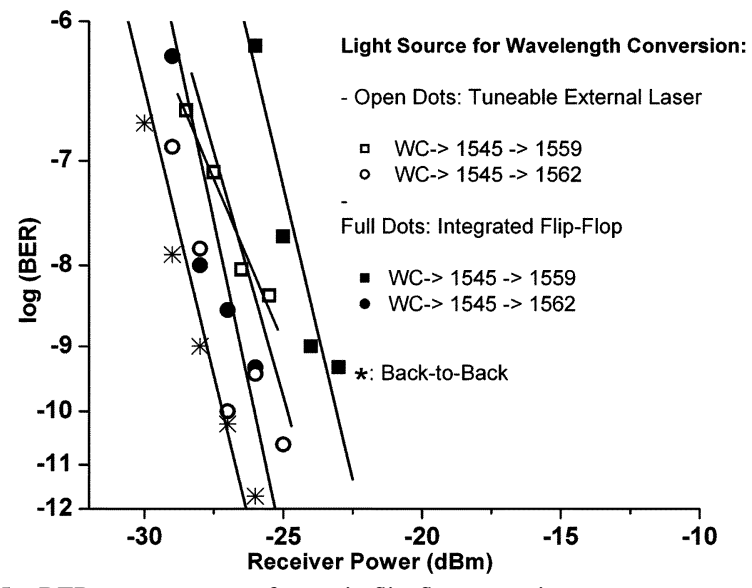

Fig. 5. BER measurements for static flip-flop operation.

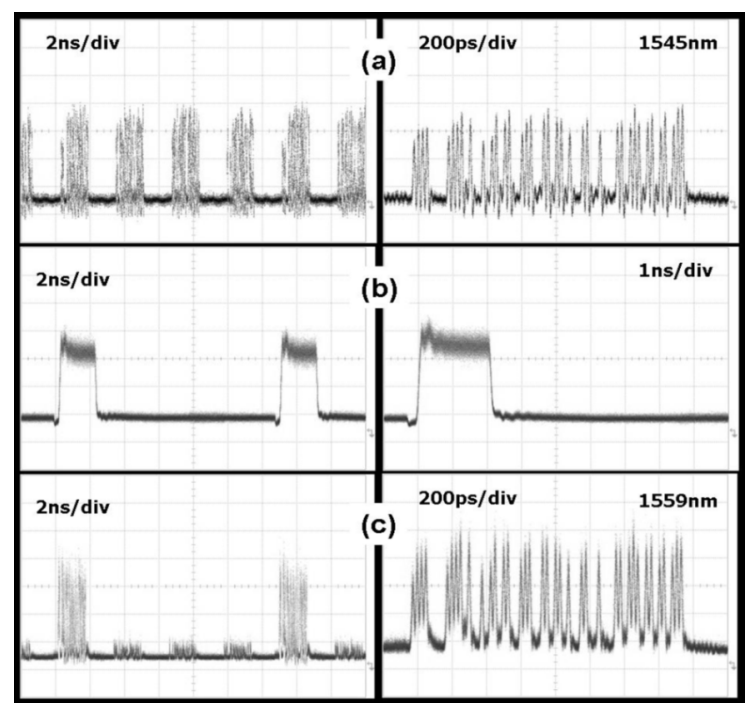

Fig. 6. Eye patterns showing all-optical routing. (a) Incoming packets, (b) flip-flop output, (c) wavelength-switched packets.

(BERs) were measured using continuous $40-\mathrm{Gb} / \mathrm{s}$ data. Specifically, the flip-flop state was controlled so as either the 1559 or $1562 \mathrm{~nm}$ was the dominant state. Fig. 5 shows the BER measurements for back-to-back and wavelength conversion using $\mathrm{CW}$ light from a tunable laser source and from CW light provided by the flip-flop. The power penalty was measured to be less than $1.6 \mathrm{~dB}$ when wavelength converting from the tunable source and the flip-flop prototype for both wavelengths. There was a polarization drift between the transmitter and the optical subsystems due to the implementation using long fibers and bulk fiber-pigtailed components, which gave a small fluctuation during the BER measurements. The polarization drift affected the input signals to the flip-flop and the wavelength converter, due to the polarization dependence of the silica motherboard. Higher stability can be obtained by minimizing the length of the fiber interconnections between the active and passive components or the implementation of the subsystems on a single chip [11]. The flip-flop was operated using the pulsed signal to achieve dynamic switching between states. The RESET pulse was delayed $2 \mathrm{~ns}$ with respect to the SET pulse, corresponding to the duration of a single packet. Data packets were produced by programming the $40-\mathrm{Gb} / \mathrm{s}$ pattern generator to produce $1.6-\mathrm{ns}$ packets separated by 2.7 ns. Fig. 6 shows oscilloscope traces.
Fig. 6(a) shows the incoming packets, and Fig. 6(b) shows the $\mathrm{CW}$ generated from the optical flip-flop, when triggered by the SET and RESET pulses. Fig. 6(c) shows the corresponding wavelength-converted packets. The flip-flop exhibited an extinction ratio of $8.5 \mathrm{~dB}$, which was the main reason of crosstalk from remaining packets. The SOAs were driven with 150 and $340 \mathrm{~mA}$ in the flip-flop and the wavelength converter, respectively. The SET/RESET optical signals were found to be polarization-independent and no significant signal-to-noise ratio degradation was observed at the output of the system. The reduced extinction ratio of the flip-flop can be enhanced by using a $2 \mathrm{R}$ regenerator at the processor/node output in order to allow for new data packets to be inserted. Higher extinction ratio greater than $20 \mathrm{~dB}$ can also be achieved by optimizing the current device design or utilizing a different flip-flop configuration [10]. In the case where more label bits are required, a feedback-based XOR correlator can be used [9]. The flip-flop prototype has two independent MZI optical flip-flops for generating four different wavelengths. Hence, a single device is sufficient for a $4 \times 4$ core node.

\section{CONCLUSION}

We have demonstrated that all-optical network subsystems can be built by functional interconnection of SOA-MZI based integrated devices. Successful label recognition and optically controlled wavelength conversion of short optical packets was shown with fast-switching prototypes.

\section{REFERENCES}

[1] A. Viswanathan, N. Feldman, Z. Wang, and R. Callon, "Evolution of multiprotocol label switching," IEEE Commun. Mag., vol. 36, no. 5, pp. 165-173, May 1998.

[2] K. G. Vlachos, I. T. Monroy, A. M. J. Koonen, C. Peucheret, and P. Jeppesen, "STOLAS: Switching technologies for optically labeled signals," IEEE Commun. Mag., vol. 41, no. 11, pp. 43-49, Nov. 2003.

[3] J. Hu et al., "Error-free multi-hop cascaded operation of optical label switching routers with all-optical label swapping," presented at the OFC 2003, Anaheim, CA, Paper FS1.

[4] D. Wofson et al., "All-optical asynchronous variable-length optically labeled 40 Gbps packet switch," presented at the ECOC 2005, Glasgow, Scotland, Postdeadline paper Th4.5.1.

[5] V. Lal et al., "Monolithic widely tunable optical packet forwarding chip in InP for all-optical label switching with $40 \mathrm{Gbps}$ payloads and 10 Gbps labels," in Proc. ECOC 2005, Glasgow, Scotland, vol. 6, pp. 25-26.

[6] F. Ramos, E. Kehayas, J. M. Martinez, R. Clavero, J. Marti, L. Stampoulidis, D. Tsiokos, H. Avramopoulos, J. Zhang, P. V. Holm-Nielsen, N. Chi, P. Jeppesen, N. Yan, I. T. Monroy, A. M. J. Koonen, M. T. Hill, Y. Liu, H. J. S. Dorren, R. Van Caenegem, D. Colle, M. Pickavet, and B. Riposati, "IST-LASAGNE: Towards all-optical label swapping employing optical logic gates and optical flip-flops," J. Lightw. Technol., vol. 23, no. 10, pp. 2993-3011, Oct. 2005.

[7] G. Theophilopoulos, "All optical signal processing: A glance into the future," presented at the Workshop on All-Optical Wavelength Conversion and Signal Processing for Next Generation Networks (OFC 2005), Invited Talk.

[8] D. J. Blumenthal and M. Masanovic, "LASOR (Label Switched Optical Router): Architecture and underlying integration technologies," presented at the ECOC 2005, Glasgow, Scotland, Paper We2.1.1.

[9] J. M. Martinez et al., “, presented at the ECOC 2002, Copenhagen, Denmark, 2002, Paper P.4-08.

[10] Y. Liu et al., "All-optical switching of $80 \mathrm{~Gb} / \mathrm{s}$ data packets using a wavelength converter controlled by a monolithically integrated optical flip-flop," presented at the ECOC 2005, Glasgow, Scotland, Postdeadline paper Th. 4.3.2.

[11] P. Bernasconi, L. Zhang, W. Yang, N. Sauer, L. L. Buhl, J. H. Sinsky, I. Kang, S. Chandrasekhar, and D. T. Neilson," Monolithically integrated 40-Gb/s switchable wavelength converter," J. Lightw. Technol., vol. 24, no. 1, pp. 71-75, Jan. 2006. 